\title{
SPOLM2O19
}

XIX SIMPÓSIO DE PESQUISA OPERACIONAL E LOGISTICA DA MARINHA RIO DE JANEIRO, RJ, BRASIL - 06 A 08 DE NOVEMBRO DE 2019

\section{METODOLOGIA DE ANÁLISE PONDERADA DE ATRIBUTOS APLICADA EM PLANEJAMENTO ESTRATÉGICO PARA MELHORIA DE MATURIDADE EM GERENCIAMENTO DE PROJETOS}

\author{
${ }^{* 1}$ Gustavo Domingos Pereira, ${ }^{2}$ Nathan Peixoto Oliveira \\ ${ }^{1}$ Nuclebrás Equipamentos Pesados S.A. \\ ${ }^{2}$ Université de Bordeaux, 33000, Bordéus-AQ, França \\ "gustavo.domingos@nuclep.gov.br
}

\begin{abstract}
RESUMO
Empresas necessitam de uma melhora em seus processos, produtos e serviços advindos do seu planejamento estratégico. Uma das maneiras de atingir eficiência global é através da melhoria da maturidade em gerenciamento de projetos, de forma a aumentar o desempenho organizacional e alinhar as atividades organizacionais aos objetivos estratégicos. O presente trabalho visa analisar a maturidade em gerenciamento de projetos através de um estudo de caso em uma empresa pública, utilizando uma modificação do questionário proposto por Darci Prado e analisar a implementação da metodologia de análise estratégica WAAM (Weighted Attribute Analysis Methodology) sob a ótica de maturidade em gerenciamento de projetos da companhia. Após a implementação do método, o nível de maturidade em gerenciamento de projetos foi avaliado novamente, e dada uma estruturação lógica e algorítmica de uma etapa do processo de planejamento estratégico, a empresa mostrou uma excelente melhora em sua maturidade de gerenciamento de projetos. $\mathrm{O}$ artigo possibilita ainda à comunidade científica o uso de um modelo simplista de análise estratégica com aplicabilidade na área de maturidade em gestão de projetos.
\end{abstract}

Palavras-chave: Gestão de Projetos; Maturidade; Planejamento Estratégico.

\section{WEIGHTED ATTRIBUTE ANALYSIS METHODOLOGY APPLIED IN STRATEGIC PLANNING FOR PROJECT MANAGEMENT MATURITY IMPROVEMENT}

\begin{abstract}
Companies need an improvement in their processes, products and services that come from their strategic planning. One of the ways to achieve overall efficiency is by improving project management maturity to increase organizational performance and align organizational activities with strategic objectives. The present work aims to analyze the project management maturity through a case study in a public company, using a modification of the questionnaire proposed by Darci Prado and to analyze the implementation of the WAAM (Weighted Attribute Analysis Methodology) from the perspective of project management maturity of the company. After implementing the method, the project management maturity level was reassessed, and given a logical and algorithmic structuring of one step of the strategic planning process, the company showed an excellent improvement in its project management maturity. The article also allows the scientific community to use a simplistic model of strategic analysis with applicability in the area of project management maturity.
\end{abstract}


Keywords: Project Management; Maturity; Strategic Planning.

\section{Como Citar:}

PEREIRA, Gustavo Domingos; OLIVEIRA, Nathan Peixoto. etodologia de análise ponderada de atributos aplicada em planejamento estratégico para melhoria de maturidade em gerenciamento de projetos Previous. In: SIMPÓSIO DE PESQUISA OPERACIONAL E LOGÍSTICA DA MARINHA, 19., 2019, Rio de Janeiro, RJ. Anais [...]. Rio de Janeiro: Centro de Análises de Sistemas Navais, 2019.

\section{INTRODUÇÃO}

\subsection{APRESENTAÇÃO DO TEMA}

Empresas deparam-se com a necessidade de melhor eficiência de processos e qualidade dos produtos, assim como, diminuir contratempos advindos de mal planejamento. Uma das maneiras de atingir eficiência global é através da melhoria da maturidade em gerenciamento de projetos, de forma a aumentar o desempenho organizacional e alinhar as atividades organizacionais aos objetivos estratégicos (Nascimento et al., 2014).

Este artigo, propõem-se aplicar a metodologia de análise estratégica fundamentada por Pereira (2017) que utiliza análise do ambiente externo da empresa abordando aspectos Político, Econômico, Social, Tecnológico, Ambiental e Legal (PESTAL), representando o panorama externo em que a empresa se encontra. No que tange o microambiente empresarial, a metodologia avalia as Cinco Forças de Porter, mostrando como a empresa se relaciona diretamente com seus clientes, concorrentes, fornecedores, novos players e produtos substitutos. Por fim, analisa-se os aspectos e características internas da empresa, que identifica suas individualidades como perfil comportamental dos colaboradores, localização, infraestrutura, maquinário e cultura organizacional.

O objetivo do presente trabalho é avaliar a maturidade em gerenciamento de projetos da empresa antes e após a implementação da metodologia quantitativa e qualitativa de análise estratégica e de risco Weighted Attribute Analysis Methodology (WAAM), em uma empresa de pública federal brasileira de médio porte, para que seja avaliada se houve melhora ou não na maturidade empresarial na temática de gerenciamento de projetos.

O presente trabalho está dividido em três etapas:

1. Análise de maturidade em gerenciamento de projetos antes da aplicação da metodologia;

2. Apresentação das consequências da aplicação da metodologia WAAM abordando caracterização e posicionamento estratégico da empresa, análise PESTAL, análise das Cinco Forças de Porter, análise dos aspectos e características internas, análise de riscos utilizando-se o framework proposto pelo COSO. Esta etapa não será desenvolvida e trabalhada neste trabalho. Apenas suas consequências serão analisadas, dado que seu desenvolvimento e resultados foram exaustivamente abordados por Pereira (2017), no trabalho denominado "A new methodology proposal for the implementation of a strategic-and-risk-actions PMO for portfolio management” $\mathrm{e}$

3. Análise de maturidade em gerenciamento de projetos após a aplicação da metodologia. 
O questionário proposto por Prado (2010) utilizado para análise de gerenciamento de projetos foi modificado para analisar a maturidade do projeto, focando em projetos estratégicos e de alto nível na gestão, oriundos de ações provenientes do planejamento estratégico da empresa.

Este questionário é direcionado para a diretoria executiva e gestores de alto nível na empresa, a fim de determinar suas capacidades e necessidades em gestão e gerenciamento das ações derivadas da análise estratégica e riscos estratégicos organizacionais a fim de circunstanciar a empresa no que tange gerenciamento de projetos.

O fluxograma da Figura 1 fornece um resumo da metodologia:

Figura 1 - Fluxograma da Metodologia Proposta.

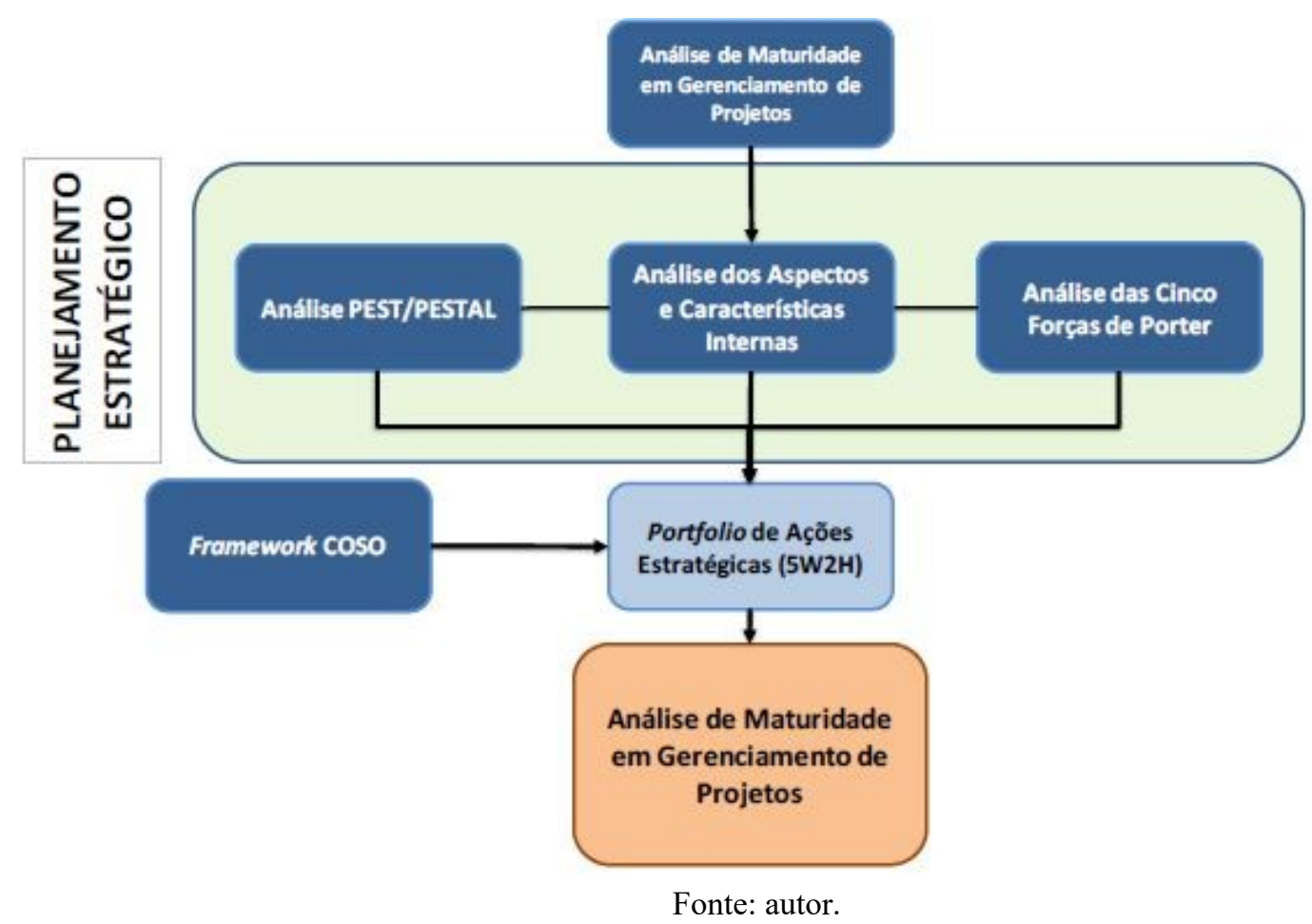

\section{FUNDAMENTAÇÃO TEÓRICA}

\subsection{ANÁlise PESTAL}

O acrônimo PEST é uma abreviatura para Político, Econômico, Social e Tecnológico (CASTOR, 2000). Conhecida como análise PEST, a metodologia consiste em uma identificação de variáveis macro ambientais relacionados aos aspectos externos em que a empresa está inserida ou deseja avaliar a possibilidade de entrada, caso pretenda iniciar suas operações em outros países. Adicionalmente, foram incluídos ao longo do tempo outros fatores que, adicionados ao modelo PEST, complementam a análise. Estes fatores seriam: Legal e Ambiental que, adicionados ao acrônimo PEST, gera o acrônimo STAPLE ou PESTAL.

Segundo Kotter e Schlesinger (1991), quando se analisa o macro ambiente, é importante identificar os fatores que podem influenciar direta ou indiretamente a empresa, quer seja em níveis de demanda do mercado ou em custo. A empresa normalmente é incapaz de controlar estas influências, podendo apenas identificá-las e se preparar para mitigar seus efeitos. 
Esses aspectos externos à empresa possuem impacto no funcionamento de toda a organização, segundo Tsiakkiros (2002), dada a incessante e intensa mudança que ocorre no ambiente em que a empresa se insere.

Os fatores políticos expressam o quanto o governo intervém ativamente na economia. Alguns países possuem incentivos ou dificultam o acesso para entrada de uma nova empresa no mercado, seja ela estrangeira ou não. Há a necessidade de se avaliar os aspectos políticos como estímulo à determinados setores, taxação setorial, leis trabalhistas, burocracia, alfândega, regime político, estabilidade política, etc.

\subsection{Análise das Cinco ForÇas de Porter}

Porter (1986) estipula que cinco forças determinam a dinâmica da competição em uma indústria: a entrada de novos concorrentes, a ameaça de substitutos, o poder de barganha dos clientes, o poder de barganha dos fornecedores e a rivalidade entre os concorrentes atuais.

Através de sua análise, pode-se encontrar um panorama para a empresa em relação à sua rentabilidade e competitividade para com empresas em seu nicho de mercado. Estas forças servem como base e parâmetro para que a empresa desenvolva um posicionamento estratégico perante o mercado, necessitando rever constantemente suas mudanças dado que as mesmas produzem uma influência no comportamento estratégico da empresa.

Estas forças atuam em conjunto com a análise SWOT, servindo como input de dados para posicionar estrategicamente a empresa em seu microambiente, macro ambiente e também quanto à suas características internas. Porter (1986) denominou as cinco forças como horizontais e verticais. As forças horizontais consistem da Ameaça de Novos Entrantes, Ameaça de Produtos Substitutos e Intensidade da Concorrência, enquanto as forças verticais consistem em Poder de Barganha dos Fornecedores e Poder de Barganha dos Clientes.

\subsection{Análise do AMbiente Organizacional}

A análise do ambiente organizacional foi a primeira análise a ser realizada para estruturar um posicionamento estratégico da empresa, tendo em vista que as características internas da organização interferem diretamente em suas capacidades estratégicas, tanto como pontos positivos quanto pontos negativos. Estas características refletem fatores como a maneira que a cultura da empresa e empregados é expressada, sua localização, seu sindicato, sua direção, entre outros fatores intrínsecos da mesma.

Um conceito chamado de cadeia de valor foi utilizado para que os pontos fortes e fracos da empresa fossem analisados em cada uma das etapas de geração de valor através da cadeia, somados com aspectos simples de cultura e clima organizacional.

Porter (1985) introduz o conceito de cadeia de valor empresarial, que representa o conjunto de atividades desempenhadas por uma organização em todas as fases envolvidas nos processos de criação de um produto ou serviço. Cada uma representando respectivamente suas características positivas e negativas, sendo elas: infraestrutura da empresa, gestão de recursos humanos, desenvolvimento de tecnologia, aprovisionamento, logística de entrada, operações, logística de saída, marketing e vendas e serviços.

\subsection{Análise de Maturidade de Empresas em Gerenciamento de Projetos}

O Gerenciamento de Projetos exige técnica, boas práticas e melhoria contínua. Alcançar o sucesso na realização dos mesmos envolve uma gama de critérios a serem aceitos para os parâmetros, quer seja por clientes, prazos, requisitos de qualidade, orçamento ou especificações técnicas.

Cada empresa possui seu histórico particular de gerenciamento dos projetos que executa, assim como seu conjunto particular de técnicas escolhidas baseadas no que julgou ser o modelo de gestão mais pertinente para a mesma. 
Segundo o PMI (2013), o gerenciamento de projetos pode ser denominado como a aplicação de habilidades, metodologias, técnicas, conhecimentos para a elaboração e execução de atividades para atingir um objetivo. O grau em que a organização utiliza os conhecimentos de determinado conjunto de metodologias para gerenciamento de projetos se chama Maturidade em Gerenciamento de Projetos. A entidade organizacional responsável pelo gerenciamento coordenado dos projetos executados se chama PMO (Project Management Office).

\subsection{Fundamentos Gerais de PMO}

Ireland e Cleland (2002) definem projeto como um trabalho de execução única, possuindo início e fim claramente especificados, com objetivos e escopo bem definidos, a ser finalizado integralmente após sua conclusão.

Em um mundo coorporativo extremamente competitivo no século XXI, as empresas possuem a necessidade de diminuir seus custos operacionais e otimizar seus processos e projetos sendo, portanto, segundo Rad e Raghavan (2000), uma das áreas de estudo que mais crescem no mundo atualmente.

O PMI (2013) define o escritório de gerenciamento de projetos (PMO) como uma unidade organizacional que é responsável por coordenar e gerenciar os projetos de uma organização, supervisionando, apoiando, administrando e priorizando os mesmos.

\subsection{Fundamentos Gerais de ANÁlise de Risco}

Todas as organizações enfrentam incertezas e é justamente por isso que o gerenciamento de riscos é uma ferramenta crucial de análise relativa aos riscos que a empresa está disposta a aceitar e como se encontra balanceada a relação entre risco e retorno.

Hall (2001) define risco, como uma medida da probabilidade e das perdas acarretadas pelo acontecimento de um evento que possa afetar negativamente o projeto, processo ou produto. O risco também pode ser interpretado com a interação intencional com a incerteza (CLINE, 2004), já que a incerteza é um resultado potencial, imprevisível e incontrolável e o risco é a consequência da ação tomada independente da incerteza (ANTUNES; GONZALEZ, 2015).

\subsection{Fundamentos Gerais de Gerenciamento de Portfolio}

A gestão e gerenciamento de portfólios de projetos é definida por Carvalho e Junior (2008) como um conjunto de modelos, procedimentos e processos que possuem o objetivo de administrar e executar projetos empresarias de forma sistêmica. estratégia.

A carteira de projetos deve estar relacionada com a missão da empresa e aderir à sua

Quando uma carteira de gerenciamento de projetos é derivada do planejamento estratégico, o conjunto de ações e metas devem estar direcionados para a execução e cumprimento das decisões advindas deste planejamento estratégico. O PMI (2008) diz que a gestão de portfólio tem como objetivo a estruturação e coordenação dos projetos pertencentes ao portfólio com o intuito de atingir as metas definidas no planejamento.

A melhoria contínua destes projetos pertencentes ao portfólio é inerente à própria natureza estratégica dos projetos e das ações necessárias para sua execução. A evolução, resultado e viabilidade dos projetos pertencentes ao portfólio devem sofrer revisão constante.

A gestão de portfólio engloba uma gestão simultânea de vários projetos constituintes do mesmo, para que seja atingido um objetivo estratégico.

Uma estrutura de governança de portfólio é imprescindível para empoderar, definir e dar suporte ao gerenciamento de projetos, programas e portfólio dentro das empresas (ALMEIDA; ALMEIDA, 2013). 
Kendall e Rollins (2003) dizem que o papel dessa governança de portfólio é de direção e decisão acerca da priorização dos projetos pertencentes ao portfólio.

\section{DESCRIÇÃO E ANÁLISE DO PROBLEMA}

A empresa a ser analisada é uma empresa brasileira federal que responde diretamente ao governo, sendo responsável pela fabricação de submarinos, submarinos nucleares, componentes das usinas nucleares, como vasos de pressão, trocadores de calor e todo o tipo de equipamento que necessita de um rigor de qualidade alto ou que sejam excessivamente grandes em termos de dimensões, com alta espessura ou grandes massa.

Com a descontinuação do programa nuclear brasileiro e a incerteza perante a crise financeira, a empresa se encontrou na necessidade de abordar novos mercados e expandir seu leque de atuação, não somente atuando no mercado nuclear, mas também em mercados estratégicos em que a empresa poderia operar.

A empresa se encontra há anos certificada pela norma ISO 9001, cuja nova versão requer uma metodologia empresarial de gerenciamento de riscos para recertificação, além da nova diretriz governamental que todas as empresas federais necessitam ter um planejamento estratégico estruturado e realizado uma vez a cada ano.

\subsection{Proposta de Implementação da Metodologia de AnÁlise Estratégica}

A proposta de solução para análise estratégica e riscos da empresa foi estruturada de forma metodológica, que não será abordada extensivamente no presente trabalho. Está foi iniciada com um questionário de maturidade em gerenciamento de projetos proposto por Darci Prado (2010). Em sequência, foram feitas, análise PESTAL, análise das Cinco Forças de Porter e da análise dos fatores internos.

As análises PESTAL e dos fatores internos foi feita levantando-se os pontos positivos e negativos respectivos à cada fator da análise seguidas da atribuição de um ou mais eventos de risco advindas destes pontos positivos e negativos.

Similarmente, a análise das Cinco Forças de Porter foi feita relacionando os fatores influentes à empresa para cada uma das cinco forças, seguidas da atribuição também de um ou mais eventos de risco advindas da análise.

Inicialmente, a proposta foi que somente fosse elaborado um plano de ação para as ameaças e pontos negativos aos quais a empresa estava sujeita estando cada fator sujeito a apenas um evento de risco.

Os fatores que possuíram maiores influências e maiores riscos foram selecionados para compor o plano de ação, onde os objetivos traçados estavam atrelados à suas respectivas respostas aos riscos, podendo ser aceitar, mitigar, dividir, transferir ou eliminar.

Após a seleção do plano de ação, o mesmo questionário de maturidade em gerenciamento de projetos baseado numa modificação do questionário elaborado por Darci Prado foi aplicado, de modo a determinar qual o nível de maturidade da empresa em termos de gerenciamento de projetos após a estruturação desta nova metodologia de planejamento estratégico.

Este questionário foi modificado do questionário original para abranger a corporação como um todo.

Através de uma avaliação macro ambiental para localizar estrategicamente a empresa e como ela está inserida no mercado, foi utilizado a análise PESTAL.

Em conjunto, foi utilizada uma análise baseada nas Cinco Forças de Porter, para estabelecer o microambiente em que a empresa se encontra.

\subsubsection{Análise PEST/PESTAL}

Para cada item da análise PESTAL, foram selecionados fatores para aspectos 
positivos e negativos, sendo atribuídos a cada fator um evento de risco e quantificado um grau de intensidade de impacto, um grau de relevância para a empresa e uma probabilidade de ocorrência, podendo os três assumirem valores de 1 (baixo) até 10 (alto).

\subsubsection{Análise das Cinco Forças de Porter}

Para cada item relativo à cada Força de Porter, foram atribuídos a cada fator um evento de risco e quantificado um grau de intensidade de impacto, um grau de relevância para a empresa e uma probabilidade de ocorrência, podendo os três assumirem valores de 1 (baixo) até 10 (alto). A relevância para a empresa para cada item da análise das Cinco Forças de Porter foi escolhida levando em consideração uma média subjetiva de cada um dos itens a seguir:

\section{Fornecedores}

Os critérios escolhidos para a análise da relevância dos fornecedores foram:

a) Concentração no mercado: indica a concentração no mercado de fornecedores da respectiva matéria prima. Quanto maior o valor, melhor para a empresa;

b) Diferenciação do produto: indica o quanto a matéria prima possui diferenciação. Quanto menor o valor, melhor para a empresa;

c) Custo de mudança de fornecedor: indica o grau de impacto para a empresa caso opte por mudar de fornecedor da respectiva matéria prima. Quanto menor o valor, melhor para a empresa;

d) Dificuldade de substituição: indica o grau de dificuldade da empresa em substituir a respectiva matéria prima por um substituto. Quanto menor o valor, melhor para a empresa;

e) Quantidade de substitutos: indica a quantidade de substitutos existentes no mercado para a respectiva matéria prima. Quanto maior o valor, melhor para a empresa;

f) Volume de compras: indica o volume de compras por parte da empresa em relação ao total de compras do fornecedor. Quanto maior o valor, melhor para a empresa;

g) Frequência de compras: indica a frequência de compras por parte da empresa da matéria prima em questão. Quanto maior o valor, melhor para a empresa.

\section{Clientes}

Os critérios escolhidos para a análise da relevância dos clientes foram:

a) Concentração no mercado: indica a concentração no mercado de compradores dos produtos da empresa. Quanto maior o valor, melhor para a empresa;

b) Volume de compras: indica o volume de compras por parte do cliente em questão. Quanto menor o valor, melhor para a empresa.

c) Custo de mudança para os compradores: indica o custo de mudança de fornecedor do produto para uma empresa concorrente. Quanto mais o valor, melhor para a empresa;

d) Importância das compras para o comprador: indica o grau de importância dos produtos da empresa para o comprador em questão;

e) Custo relativo ao total do comprador: indica o custo dos produtos da empresa em relação às compras do cliente em questão. Quanto menor o valor, melhor para a empresa;

f) Dificuldade de substituição: indica a dificuldade de substituição do produto por parte do cliente para um produto similar. Quanto maior o valor, melhor para a empresa;

g) Diferenciação do produto: indica o grau de diferenciação do produto ofertado pela empresa. Quanto maior o valor, melhor para a empresa.

h) Frequência de compras: indica a frequência de compras do cliente em relação ao produto em questão. Quanto menor o valor, melhor para a empresa.

\section{Competidores}

Os critérios escolhidos para a análise da relevância dos competidores foram: 
a) Concentração de mercado: indica a concentração de competidores do produto em questão no mercado. Quanto menor o valor, melhor para a empresa;

b) Lealdade relativa do consumidor: indica o grau de lealdade do consumidor em relação ao produto competidor ao da empresa. Quanto menor o valor, melhor para a empresa;

c) Porte relativo: indica o porte relativo do competidor em questão à empresa. Quanto menor o valor, melhor para a empresa;

d) Custo relativo: indica o custo relativo de fornecimento de produto do competidor em questão. Quanto maior o valor, melhor para a empresa;

e) Prazo relativo: indica o prazo de entrega relativo de fornecimento de produto do competidor em questão. Quanto maior o valor, melhor para a empresa;

f) Crescimento na indústria: indica o grau de crescimento do competidor em questão. Quanto menor o valor, melhor para a empresa;

g) Diferenciação do produto: indica a diferenciação relativa do produto do competidor em questão. Quanto menor o valor, melhor para a empresa;

h) Agressividade de marketing: indica o investimento no marketing do competidor em questão. Quanto menor o valor, melhor para a empresa.

\section{Substitutos}

Os critérios escolhidos para a análise da relevância dos substitutos foram:

a) Concentração de mercado: indica a concentração de substitutos do produto em questão no mercado. Quanto menor o valor, melhor para a empresa;

b) Qualidade relativa: indica o grau de qualidade relativa do produto do substituto aos da empresa. Quanto menor o valor, melhor para a empresa;

c) Custo de mudança para os compradores: indica o custo de mudança do consumidor para um produto substituto. Quanto maior o valor, melhor para a empresa;

d) Dificuldade de substituição: indica a dificuldade que o consumidor tem em substituir o produto em questão. Quanto maior o valor, melhor para a empresa;

e) Crescimento do mercado dos substitutos: indica o grau de crescimento da empresa substituta do produto em questão. Quanto menor o valor, melhor para a empresa;

f) Lealdade relativa do consumidor: indica o grau de lealdade do consumidor em relação ao produto substituto ao da empresa. Quanto menor o valor, melhor para a empresa;

g) Diferença de finalidade relativa: indica o grau de afastamento da finalidade do produto substituto em questão. Quanto maior o valor, melhor para a empresa;

h) Diferenciação do produto: indica a diferenciação relativa do produto substituto em questão. Quanto menor o valor, melhor para a empresa;

\section{Novos Entrantes}

Os critérios escolhidos para a análise da relevância dos novos entrantes foram:

a) Necessidade de investimento: indica o grau de necessidade de aporte monetário para o início do investimento no mercado em questão. Quanto maior o valor, melhor para a empresa;

b) Barreiras de entrada: indica o grau de dificuldade imposto pelo mercado em questão para entrada de novos fornecedores. Quanto maior o valor, melhor para a empresa;

c) Possibilidades de retaliação empresarial: indica o grau de possibilidade de retaliação por parte dos fornecedores existentes no mercado em questão para custo de mudança para os compradores: indica o custo de mudança do consumidor para um produto substituto. Quanto maior o valor, melhor para a empresa;

d) Lealdade relativa do consumidor: indica o grau de lealdade do consumidor em relação ao produto substituto ao da empresa. Quanto maior o valor, melhor para a empresa; 
e) Necessidade de economias de escala: indica a necessidade de entrar no mercado com uma grande quantidade de produtos por lote. Quanto maior o valor, melhor para a empresa;

f) Necessidade de curva de aprendizado: indica a necessidade de uma curva de aprendizado para os produtos da indústria em questão. Quanto maior o valor, melhor para a empresa.

g) Rentabilidade do mercado: indica o grau de rentabilidade e atratividade do mercado em questão. Quanto menor o valor, melhor para a empresa;

h) Necessidade de divulgação: indica o grau de necessidade de investimento em propaganda e marketing. Quanto maior o valor, melhor para a empresa.

\subsubsection{Análise dos Aspectos Internos}

A análise dos aspectos internos da empresa é um dos fatores mais importantes da avaliação para seu posicionamento econômico e estratégico no mercado, assim como para a análise de risco. A participação de todos os funcionários é importante para que sejam levantadas informações verossímeis e que retratem fielmente a realidade vista de todos os pontos internos da empresa.

A análise dos fatores internos é feita como uma combinação da análise PESTAL e da análise das Cinco Forças de Porter. Para cada fator da análise interna, serão selecionados fatores para aspectos positivos e negativos, sendo atribuídos a cada fator um evento de risco e quantificado um grau de intensidade de impacto, um grau de relevância para a empresa e uma probabilidade de ocorrência, podendo os três assumirem valores de 1 (baixo) até 10 (alto).

\subsubsection{Proposta de Plano de Ação, PMO e Gerenciamento de Portfólio}

Foi sugerida a implementação de um Controlling-Strategic PMO coorporativo, para gerenciar projetos de implementação de ações estratégicas a partir do planejamento estratégico e de riscos, cujo cliente são os próprios setores da empresa. Os processos e a documentação a serem desenvolvidos pelo PMO para que ele seja capaz de gerenciar estes projetos encontram-se a seguir. Os detalhes dos processos de geração de um plano de ação foram omitidos por serem classificados como sigilosos, mas pode-se dizer que este plano de ação foi derivado das análises realizadas no presente trabalho.

\subsubsection{Gerenciamento do Escopo dos Projetos}

O gerenciamento do escopo do projeto contempla as técnicas escolhidas para definir, validar e controlar o escopo do produto e do projeto em si, de forma a garantir que a execução do projeto resulte no sucesso do comprimento dos requisitos, características e objetivos do resultado final.

a) Plano de Gerenciamento do Escopo - apresenta uma descrição de como o escopo do projeto vai ser definido, monitorado e controlado. Neste documento são definidos:

i. Metodologia de preparo do escopo do projeto;

ii. Metodologia e aprovação da EAP;

iii. Metodologia de aprovação de entregas;

iv. Metodologia de aprovação de alterações;

v. Metodologia de controle do escopo;

vi. Metodologia da criação da Matriz de Responsabilidades;

vii. Metodologia de aprovação de alterações;

b) Plano de Gerenciamento dos Requisitos - apresenta uma descrição de como os requisitos do projeto vão ser definidos. Neste documento são definidos:

i. Metodologia de priorização dos requisitos;

ii. Metodologia de controle dos requisitos; 
iii. Metodologia de coleta de requisitos;

Através da definição desses dois documentos, o documento de resumo do projeto é determinado através do Termo de Abertura do Projeto - TAP. Um exemplo de TAP segue a metodologia do $5 \mathrm{w} 2 \mathrm{~h}$ e possui as seguintes informações:

i. Nome, código e versão do projeto;

ii. Justificativa do projeto;

iii. Descrição do projeto com seus produtos, cronograma, local, data de início e custo estimado;

iv. Gerente e equipe do projeto;

v. Descrição do escopo do projeto com seus requisitos;

vi. Descrição da metodologia de execução;

vii. EAP;

viii. Matriz de responsabilidades;

\subsubsection{Gerenciamento do Tempo dos Projetos}

O gerenciamento do tempo do projeto contempla as técnicas escolhidas para planejar, definir e controlar o cronograma das fases do projeto, de forma a garantir que as durações da atividade estejam de acordo com o planejado.

a) Plano de Gerenciamento do Cronograma - apresenta uma descrição de como o cronograma do projeto vai ser definido, monitorado e controlado. Neste documento são definidos:

i. Metodologia de definição das atividades;

ii. Metodologia de sequenciamento e dependência de atividades;

iii. Metodologia de definição da duração das atividades;

iv. Metodologia de aprovação de alterações;

v. Metodologia de controle do cronograma;

vi. Metodologia de estimativa de custos das atividades;

vii. Metodologia do gerenciamento do valor agregado;

viii. Metodologia da aprovação de cronograma;

Através da definição desse documento, o cronograma do projeto estratificado por atividades é determinado.

\subsubsection{Gerenciamento dos Custos dos Projetos}

O gerenciamento dos custos do projeto contempla de técnicas escolhidas para planejar, definir e controlar os custos das fases do projeto e de seu orçamento, de forma a garantir que os custos das atividades estejam de acordo com o planejado.

a) Plano de Gerenciamento dos Custos - apresenta uma descrição de como o orçamento e custos do projeto vão ser definidos, monitorados e controlados. Neste documento são definidos:

i. Metodologia de estimativa de custos das atividades;

ii. Metodologia de reservas de contingência;

iii. Metodologia de custeio de riscos;

iv. Metodologia de definição do orçamento;

v. Metodologia de aprovação de alterações;

vi. Metodologia de controle dos custos;

vii. Metodologia de análise de desempenho dos custos;

Através da definição desse documento, o orçamento e custos do projeto estratificados por atividades são determinados. 


\subsubsection{Gerenciamento da Qualidade dos Projetos}

O gerenciamento da qualidade projeto contempla de técnicas escolhidas para planejar, definir e controlar a metodologia da garantia de qualidade do projeto, de forma a garantir que os requisitos sejam cumpridos e a qualidade esperada seja atendida.

a) Plano de Gerenciamento da Qualidade - apresenta uma descrição de como a qualidade e aceitação do projeto vão ser definidos, monitorados e controlados. Neste documento são definidos:

i. Metodologia de estruturação do PDCA e melhoria contínua;

ii. Metodologia da criação de histogramas, fluxogramas, gráficos de Pareto, diagramas de causa e efeito, diagramas de dispersão e quaisquer outras formas de controlas as varáveis do projeto;

iii. Metodologia de Benchmarking;

iv. Metodologia de definição das métricas e valores de referência para avaliação de qualidade;

v. Metodologia de aprovação de alterações;

vi. Metodologia de avaliação e criterização de não conformidades;

vii. Metodologia de estruturação de auditorias internas; determinado.

Através da definição desse documento, o plano de controle da qualidade é

\subsubsection{Gerenciamento dos Recursos Humanos dos Projetos}

O gerenciamento dos recursos humanos do projeto contempla de técnicas escolhidas para treinar, desenvolver, caracterizar e gerir a equipe do projeto, de forma a garantir que os recursos humanos sejam utilizados da maneira mais eficiente possível.

a) Plano de Gerenciamento dos Recursos Humanos - apresenta uma descrição de como os recursos humanos serão treinados, desenvolvidos, caracterizados e geridos. Neste documento são definidos:

i. Metodologia da criação e definição do organograma;

ii. Descrição e escopo de trabalho dos cargos;

iii. Metodologia de definição da Matriz RACI (Responsável, Responsável pela Aprovação, Consultar e Informar);

iv. Metodologia do plano de treinamentos;

v. Metodologia de reconhecimento e recompensas;

vi. Metodologia deaplicação de teste de dominância cerebral;

vii. Metodologia de aplicação do teste de perfis de Belbin;

viii. Metodologia de contratação, mudança de setor e demissão;

ix. Metodologia de avaliação de desempenho;

Através da definição desse documento, o plano de gerenciamento de recursos humanos é determinado.

\subsubsection{Gerenciamento das Comunicações dos Projetos}

O gerenciamento das comunicações contempla de técnicas escolhidas para armazenar, compartilhar e analisar as informações, conhecimentos e lições aprendidas ao longo do projeto.

a) Plano de Gerenciamento das Comunicações - apresenta uma descrição de como a comunicação será elaborada, desenvolvida e implementada. Neste documento são definidos:

i. Metodologia da definição de meios de comunicação oficiais;

ii. Metodologia de definição de comunicação externa com Stakeholders;

iii. Metodologia da caracterização da urgência e sigilo das informações;

iv. Metodologia de elaboração de reuniões; 
v. Metodologia de arquivamento de lições aprendidas; é determinado.

Através da definição desse documento, o plano de gerenciamento das comunicações

\subsubsection{Gerenciamento dos Riscos dos Projetos}

O gerenciamento dos riscos contempla de técnicas escolhidas para identificar, analisar, mitigar e controlar riscos potenciais ao projeto.

a) Plano de Gerenciamento dos Riscos - apresenta uma descrição de como os riscos serão identificados, controlados e geridos. Neste documento são definidos:

i. Metodologia da identificação de riscos;

ii. Metodologia de análise qualitativa de riscos;

iii. Metodologia de análise quantitativa de riscos;

iv. Metodologia de resposta aos riscos;

v. Metodologia de controle e monitoramento de riscos;

Através da definição desse documento, o plano de gerenciamento das aquisições é determinado.

\subsubsection{Gerenciamento das Aquisições dos Projetos}

O gerenciamento das aquisições contempla de técnicas escolhidas para identificar, conduzir e controlar as aquisições necessárias para o projeto.

a) Plano de Gerenciamento das Aquisições - apresenta uma descrição de como as aquisições serão levantadas e monitoradas. Neste documento são definidos:

i. Metodologia de levantamento e caracterização de aquisições necessárias;

ii. Metodologia de tomada de decisão em relação à aquisições;

iii. Metodologia de condução de aquisições;

iv. Metodologia de controle de aquisições; determinado.

Através da definição desse documento, o plano de gerenciamento das aquisições é

\subsubsection{Gerenciamento das Partes Interessadas dos Projetos}

O gerenciamento das partes interessadas contempla de técnicas escolhidas para identificar, relacionar, engajar e controlar as partes interessadas do projeto.

a) Plano de Gerenciamento das Partes Interessadas - apresenta uma descrição de como as partes interessadas serão envolvidas, trabalhadas e monitoradas. Neste documento são definidos:

i. Metodologia de realização de pesquisa de satisfação;

ii. Metodologia de identificação das partes interessadas;

iii. Metodologia de classificação das partes interessadas;

iv. Metodologia de engajamento das partes interessadas;

Através da definição desse documento, o plano de gerenciamento das partes interessadas é determinado.

\subsubsection{Gerenciamento da Integração dos Projetos}

O gerenciamento da integração do projeto contempla de técnicas escolhidas para integrar as outras nove áreas de conhecimentos do projeto.

a) Plano de Gerenciamento da Integração - apresenta uma descrição de como a integração do projeto será feita, abordando todas as outras áreas de conhecimento.

Neste documento são definidos:

i. Metodologia de realização dos planos do projeto;

ii. Metodologia de gerenciamento de mudanças; 
iii. Metodologia de gerenciamento da configuração;

iv. Metodologia de gerenciamento do andamento do projeto;

v. Metodologia de abertura do projeto;

vi. Metodologia de encerramento do projeto; determinado.

Através da definição desse documento, o plano de gerenciamento do projeto é

\section{CONSIDERAÇÕES FINAIS}

Neste trabalho foi criada uma metodologia para análise estratégica e de risco e realizado um estudo de caso aplicado à uma empresa pública federal brasileira.

Foram obtidos números extensos de informações acerca da análise PESTAL, das Cinco Forças de Porter e Análise Interna, que foram utilizadas para geração de gráficos e relatórios que servirão de base para que a alta direção da empresa tenha fundamentação para tomada de decisão, mas que não foram trabalhados neste texto dado o seu grau de sigilo.

Uma análise empresarial de maturidade em gerenciamento de projetos foi feita para determinar o que esperar e quais tipos de resultados são possíveis através do nível de maturidade relativa ao gerenciamento de projetos que a empresa possui.

Após a implementação desta metodologia de análise estratégica, a análise de maturidade em gerenciamento de projetos foi realizada novamente, mostrando uma grande melhora no nível de maturidade da empresa no que tange gestão de projetos.

De modo a estruturar a implementação das ações oriundas desta análise, a sugestão de um PMO coorporativo para gerenciamento e controle da implementação das mesmas foi estruturado e sugerido para que este portfólio de ações estratégicas pudesse ser posto em prática.

Existe um longo caminho pela frente a ser percorrido, mas ficou claro que, dada uma estruturação lógica e algorítmica de uma etapa do processo de planejamento estratégico, a empresa mostrou uma excelente melhora em sua maturidade de gerenciamento de projetos. Cabem aos executores dos próximos trabalhos de utilizarem este fato para criar novas metodologias a fim de atingir a excelência em maturidade na gestão de projetos e portfolio.

\section{REFERÊNCIAS BIBLIOGRÁFICAS}

[1] ALMEIDA, N. e ALMEIDA, F. Metodologia de Gerenciamento de Portfólio: Teoria e Prática. Rio de Janeiro: Brasport, 2013.

[2] ANTUNES, R.; GONZALEZ, V. "A Production Model for Construction: A Theoretical Framework". Buildings. 5 (1): 209-228, 2015. doi:10.3390/buildings5010209.

[3] CARVAlHO, M. M.; JÚNIOR, R. R.; PESSÔA, M. S. de P.; LAURINDO, F. J. B.; Equivalência e completeza: análise de dois modelos de maturidade em gestão de projetos, 2008.

[4] CASTOR, B. V. J. Planejamento Estratégico em Condições de Elevada Instabilidade. Rev. FAE, Curitiba, v.3, n.2, p.1-7, maio/ago, 2000.

[5] CLINE, P. B. The Merging of Risk Analysis and Adventure Education. Wilderness Risk Management. 5 (1), p. 43-45, 2004.

[6] NAscimento, T. C.; NETO, M. V. de S.; MILITO, C. M. \& JÚNIOR, P. C. M. de O. Fatores que contribuem para a maturidade em gerenciamento de projetos: o caso de um governo estadual. R. Adm., São Paulo, v. 49, n. 2, p. 415-428, 2014. 
[7] HALL, D. "Balancing Project Risks and Opportunities" in Proceedings of the Project Management Institute Annual Seminars \& Symposium, Nashville, USA, 2001.

[8] IRELAND, L. R.; CLELAND, D. I. Gerenciamento de Projetos. 2. ed. São Paulo. LTC, 2002

[9] KENDALL, G.; ROLLINS, S. Advanced Project Portfolio Management and the PMO: multiplying ROI at warp speed. Boca Raton: J. Ross Publishing Inc., 2003.

[10] KOTTER, J. \& SCHLESINGER, L. Choosing strategies for change, Harvard Business Review, pp. 24-29, 1991.

[11] PEREIRA, G. D. (2017). A new methodology proposal for the implementation of a strategic-and-risk-actions PMO for portfolio management.

[12] PMI. The Standard for Portfolio Management. 2. ed. EUA: Project Management Institute, 2008.

[13] PMI. Um Guia do Conhecimento em Gerenciamento de Projetos. Guia PMBOK®. $5^{\text {a }}$ edição. EUA. Project Management Institute, 2013.

[14] PORTER, M. Estratégia Competitiva - Técnicas para análise de indústrias e da concorrência. $18^{\mathrm{a}}$ Edição. São Paulo-SP: Campus, 1986.

[15] PORTER, M. Vantagem Competitiva - Criando e Sustentando um Desempenho Superior. $1^{a}$ Edição. São Paulo-SP: Campus, 1985.

[16] PRADO, D. Maturidade em gerenciamento de projetos. $2^{\mathrm{a}}$ ed. INDG, 2010.

[17] RAD, P.F.; RAGHAVAN, A. Establishing an organizational project office. AACE International Transactions, ABI/INFORM Global, p.P13A, 2000.

[18] TSIAKKIROS A. Strategic planning and education: The case of Cyprus. The International Journal of Educational Management. Bradford, 2002. 